\title{
Study on Physical Account and Value Account of Sea Area Resources
}

\author{
P Wang ${ }^{1,2}, \mathrm{X} \mathrm{Lin}^{1,2}$ and Y H Yu ${ }^{1,2}$ \\ 1 National Marine Environmental Monitoring Center,Linghe Stree, Dalian,China \\ 2 Key Laboratory of Sea-Area Management Technology.SOAr,Linghe Stree, Dalian,China
}

\begin{abstract}
Conducting surveys on the status quo of sea area resources, figuring out the basic information about endowment of sea area resources, constructing an accounting standard system for sea area resource assets - value and establishing a physical account and a value account for sea area resource reserve are the foundation for sea area price evaluation and necessary conditions for the perfection of natural resource asset property rights system. This paper analyzes the survey on the status quo of sea area resources in China and the status quo of resource account and value account, brings up a problem that surveys and accountings of sea area resources cannot meet the management requirements of paid utilization of sea area and offers specific suggestions such as carrying out surveys on the space resources of sea area, evaluating the value of resources.
\end{abstract}

\section{Background}

Accounting sea area resource assets and mastering authentic, valid, systematic and complete data of the status quo of sea area are the foundation for paid utilization of sea area as well as the most basic requirement for determining China's ocean development strategic positioning, optimizing ocean industry layout, scientifically allocating sea area resources and realizing ecological utilization of sea. However, so far no systematic and complete researches have been conducted on surveys and accountings of space resources of sea area with regard to the requirements for integrated management of sea area in China except that a survey on the status quo of utilization of relevant sea area was carried out for the special project of "Comprehensive Oceanographic Survey and Evaluation of China's Coastal Seas" in 2007. Since the survey on the status quo of sea area utilization is only a part of the investigation of the status quo of sea area, thus not being able to reflect the basic situation of sea area resources, and the survey was conducted about 10 years ago, the data on the status quo of China's sea area resources is inaccurate and unclear at present.

The existing data on the status quo of sea area is no longer sufficient for China to play the role of macrocontrol in the reasonable allocation of sea area resources, thus weakening the capability to develop marine resources and hindering the transformation of marine economy into quality-benefit type. Meanwhile, for lack of reasonable evaluation on the value of sea area resources, it is very difficult to establish an asset value account for natural sea area resources and the market- oriented allocation of sea area resources advances slowly, thus not being able to meet the new requirements for marine economy development and sea area management under conditions of market economy.

Before human started to exploit the ocean on a large scale, ocean was not yet resources in terms of economics and there was no concept of scarcity. However, since human started to exploit and utilize the ocean on a large scale, there have been increasing demands for marine resources followed by the scarcity of marine resources. This kind of scarcity is very obvious in some industries and regions, which is mainly embodied in the contradiction between the total supply and total demand of marine resources, especially the contradiction in the exploitation and utilization of sea area resources resulting from the scarcity of some types of resources, such as shoreline, depth of water, and gulf resources. The degree of scarcity of sea area resources determines the price of sea area, which determines the value of sea area resource assets. Only through good utilization and management of sea area resources, can we "make the best use of everything" while enabling sea area resources to be regenerated and recycled in a good ecological environment, thus promoting the sustainable development of marine economic society. Therefore, figuring out the status quo of sea area resources and scientifically evaluating the value of sea area resources according to conditions such as location, quality, and environment of sea area resources, economic development and demands, are the foundation for paid transfer of sea area as well as a measure to protect the rights and interests of the national owner. The past ten years witnessed China's fast development of marine economy. With large-scale and 
high-intensity ocean exploitation and utilization, significant changes have taken place to environment of marine resources. If we cannot learn the status quo of sea area resources promptly and accurately or conduct scientific classification on sea area resources or scientifically evaluate the number, quality, location conditions, etc. of space resources of sea area such as gulfs and coastlines, we cannot scientifically evaluate the value of sea area resource assets, thus preventing the work of paid transfer of sea area from being carried out in an orderly manner and failing to effectively protect the rights and interests of national sea area owner.

Currently, some scholars have conducted some research on paid utilization of sea area [1-5] and natural resource assets accounting[6-8,11]. Accounting sea area resource assets and establishing a physical account and a value account are the premises for comprehensive evaluation of the natural, economic and social attributes of sea area, the foundation for sea area ranking and grading and price evaluation and necessary conditions for the perfection of natural resource asset property rights system, the guarantee of the collection of all sea area utilization fee receivable, the realization of maintenance and appreciation of the value of state-owned sea area resource assets and the performance of duties of owners of national sea area resource assets. The establishment of the two accounts can facilitate the comprehensive and scientific management of sea area, thus realizing paid utilization of sea area in a better way.

\section{Status quo of survey on sea area resources in China}

Oceanographic surveys in China started from the late 1950s. Comprehensive surveys with relatively large scale were conducted in the $70 \mathrm{~s}$ to $90 \mathrm{~s}$. Among those oceanographic surveys, most of the ones carried out in early stage were general surveys. For example, "General Oceanographic Survey of Bo Hai, Huang Hai, Dong Hai and Nan Hai" was a general survey on the basic conditions of marine environment, while "Countrywide Comprehensive Investigations of the CoastalZone and Tidalland Resources" and "General Investigation of the Country's Island Resources" were comprehensive investigations of environmental resources. However, due to the constraints of state financial resources and technical conditions, there are few measured data in all kinds of survey materials and the accuracy is relatively low, and most of the basic maps or drawings were produced by compilation.

Most of the oceanographic surveys carried out in recent years are special investigations. During 1995-2002, 20012005 and 2003-2007, various special investigations of exclusive economic zones and continental shelves were carried out in order to learn the situation of continental shelves and exclusive economic zones for the interest of China. In addition, the department concerned also carried out regional and professional marine science surveys and international cooperative studies one after another.
The latest oceanographic survey was Comprehensive Oceanographic Survey and Evaluation of China's Coastal Seas ("Special Project No. 908") which was approved by the State Council in September 2003 and organized and implemented by the State Oceanic Administration. This project includes the tasks of comprehensive oceanographic investigation, evaluation of China's Coastal Seas, and construction of the basic framework of "digital ocean" information. A total of RMB 2.059 billion had been put into the project and approximately RMB 300 million went to coastal provinces (autonomous regions or municipalities). During the implementation of the special project, advanced instruments and equipment for oceanographic survey were adopted and more than 500 ships of different sizes were used. The total voyage reached more than 2 million $\mathrm{km}$. And it took about 20 thousand days to finish operation at sea. "Special Project No. 908" mainly aimed at optimizing the existing marine function zoning, establishing marine protection plans, promoting healthy, stable and sustainable development of China's marine economy and providing technical support and scientific basis[12] for the implementation of the 2020 phased missions, goals and measures of marine power strategy.

\section{Problems}

\subsection{The existing survey materials cannot meet the management requirements of paid utilization of sea areas.}

Since the 1950s, China had successively carried out various oceanographic surveys with definite purposes in general. Some are for learning the basic conditions of continental shelves and exclusive economic zones and others for figuring out the reserve and getting the whole picture of the attributes of marine resources ("Special Project No. 908"). The problems existing mainly cover the following two aspects:

First is the purpose of the investigation. In order to meet the needs of management of paid utilization of sea area, we mainly need to understand the detailed endowment characteristics of bays, coastline, beaches, underwater topography and other space resources, the required scale is large, but the sea area resource types to be investigated are not many. The scale of "908" investigation is quite small, but there are plenty of resources to be investigated (including marine chemistry, biology, physics, economics). Because the main goal of "Special Project No. 908" is to optimize the existing marine functional zoning and formulate marine conservation planning, so as to promote the healthy, stable and sustainable development of marine economy in China, which determines that it is impossible to get full and accurate data that meet the needs of paid utilization of sea areas. It can also be said that it is impossible to accurately establish physical accounts and value accounts for marine resources.

Second is the currency of investigation. Take land investigation for example. China's first land investigation began in May 1984 and ended at the end of 1997, the 
second national land investigation was carried out from July 1, 2007 and completed in the first half of 2009. After 2010, the national annual land change investigation was carried out in China to maintain the currency of investigation results. However, since the end of the "Special Project No. 908" in 2008, no similar investigation or updating investigation has been carried out on sea area resources, which is unscientific and unreasonable.

Since 2010, marine economy has developed rapidly, the sea area utilization represented by sea reclamation rapidly changed the original coastlines, bays, beaches, water depth and other resource environments. From 2010 to 2015, continental coastlines in China increased most, which is $1,224.98 \mathrm{~km}$. The influence of human factors on coastlines is very significant. As the length of artificial coastline increases gradually, the natural coastline decreases sharply, which has decreased from $6,353.5 \mathrm{~km}$ in 2010 to $5,761.0 \mathrm{~km}$ in 2015 [9].

The bays are affected by sea reclamation and their areas are shrinking gradually. From 2010 to 2014, China's bay area dropped by $2,000 \mathrm{~km} 2$, in which the Bohai Bay area dropped most. In 2010, the proportion of bays with more than $60 \%$ natural coastline was less than $25 \%$, and that of more than $80 \%$ natural coastline was less than $5 \%$. While in 2014 , the proportion of bays with less than $40 \%(60 \%)$ natural coastline was above $71 \%(89 \%)[10]$.

The data changes of coastline and bays above are only low-precision data obtained by remote sensing, but they can explain the changing speed of space resources. The rapidly changed space environment and the old investigation materials have affected China's overall layout and overall planning on the development and utilization of sea areas. In the paid utilization of sea areas, we cannot use the accurate economic leverage to control and affect the sustainable utilization of sea area resources and orderly development of marine economy.

\subsection{The accounting of sea area resource assets cannot meet the needs of paid utilization management of sea areas.}

\subsubsection{The lack of resource investigation and accounting results in indefinite value quantity of sea area resources.}

The lack of full, accurate status quo investigation data makes it impossible to establish a physical account of sea area resource, let alone value account, because there is no scientific and reasonable value evaluation system and standards. Even if the quantity of resources in a region is clear, its value quantity still cannot be assessed. Although the release of the Technical Guidelines for Sea Assessment by the State Oceanic Administration in 2013 provided preliminary policy and technical support for the allocation of sea area resources by the market and met the requirements for the evaluation of individual projects, as to how to determine the value quantity and value of regional resources, there is still no technical method and standard. At present, the evaluation of the value of sea areas cannot meet the needs of paid utilization and market development of sea areas. Whether it be the use right remise or transfer of sea areas, or the tender, bidding, listing, mortgage, etc., we need to first determine its value; otherwise, it is difficult to carry out follow-up work with unclear resources and unknown property right.

\subsubsection{The lack of resource investigation and calculation results in insufficient support for promoting the dynamic adjustment of levy standards for sea area fees.}

Only by accurately understanding the basic situation of China's sea area resources, can it be possible to make reasonable evaluation and ranking and grading of sea areas, accurately establish sea area price and realize the paid utilization of sea areas.

In 2007, on the basis of the collected data at that time, China classified the sea areas into six levels and determined the sea area utilization fee levy standards for different sea use types on this basis. Sea area utilization fees include sea area space resource occupied fee and sea area nature change additional fee, in which the sea area space resources occupied fee is comprehensively calculated through a large number of samples, while weighted calculation is adopted through certain index systems for the sea area nature additional fee. Whether it is sample calculation or weighted calculation, it is necessary to have a detailed understanding of sea area resources.

By the degree of understanding of the sea area resources at that time, the division of sea area classification inevitably had imperfections. The sample points used in sea area utilization fee are quite different from those of land prices, and they are not even of the same order of magnitude. The "ranking" after "grading" cannot be carried out for lack of relevant research support. The advantages and disadvantages of the sea area resources in the same area cannot be reflected in value, so we cannot guarantee the sea area utilization fee can really reflect the value of the sea area.

\subsubsection{The lack of resource investigation and accounting renders the available quantity of sea area resources unable to be determined.}

In December 2011, the National Development and Reform Commission and the State Oceanic Administration jointly issued the Measures for the Administration of Reclamation Plan and carried out annual plan control for reclamation. However, the reclamation is only a specific sea use type and sea use method used in sea areas, accounting for a small proportion in sea use areas. For other sea types such as aquaculture sea use or tourism and entertainment sea use, the way of supply and the annual supply target cannot be determined. Taking Changhai County as an example, within the $6,000 \mathrm{~km}^{2}$ sea areas in its jurisdiction, more than $95 \%$ areas have gained authentic right to become an aquaculture sea. Is it appropriate and how should it be developed in the future? Only by full and accurate investigation and evaluation on sea area resource and its 
value can we determine the total supply and annual planned supply of sea area resources and realize paid and orderly use of sea areas.

\section{Recommendation}

\subsection{Carry out sea space resource investigation and establish resource physical account}

Carry out development and utilization and resource reserve investigation on typical sea space resources, which mainly includes the following contents:

(1) Investigation of bays, estuaries and beaches. Bays, estuaries and beaches are highly concentrated areas of sea area development activities. We should investigate the distribution, area and type of bays, estuaries and beaches to obtain such data as its development and utilization rate, utilization mode, output efficiency, as well as grasp the reserves of bay, estuary and beach resources and the annual loss or increase caused by natural or man-made factors.

(2) Coastline investigation. By investigating the length, types and resource endowment of China's coastline, we can figure out the length and type of coastline, the development and utilization rate of coastline, the reserves of natural coastlines and recoverable quantity. And carry out investigation on the change of coastline caused by sea area use activities, including the type, length and type of formed coastline caused by reclamation, so as to grasp the laws of change of coastline and provide basis for policy formulation of coastline resource utilization and protection.

\subsection{Carry out resource value evaluation and establish value account of sea area resources}

According to the principle of entity before value, stock before flow, classification before integration and pilot before promotion, explore and carry out asset accounting of sea area resources (Feng Zhiming etc., 2015). Establish the balance sheet of typical sea space resources, figure out the asset reserve of sea space resources and its change, comprehensively record their possession, use, consumption, recovery and value-added activities which reflect the sea space resource asset and assess the changes in physical quantity and value quantity of the sea space resource asset in the current period. Through the accounting of sea area resource asset, the sea area resource value shall be included into traditional accounting scope and related to economic activities, so as to improve the utilization efficiency of sea area resources.

\subsection{Construct the value accounting system of sea area resource asset}

\subsubsection{Construct the technical method system of sea area resource value accounting}

Study and formulate technical standards and technical regulations for the value accounting of marine resources, including technical specifications of sea area current situation investigation, classification standards and investigation technical specifications of typical sea area space resources, accounting standards for sea area resource asset and so on.

\subsubsection{Establish supply system of sea area resource plan}

The coastal provinces (cities, districts) shall determine ten-year total supply of sea area resource plan as per the actual situations of marine function zoning, marine resource characteristics, the current situation of ecological environment and economic and social development needs, and formulate the annual supply indicator according to the annual demands, then take the aquaculture sea as a pilot and gradually implement in the whole country. For sea areas with low resource environmental bearing capacity and within the marine ecological red line area, the prohibited resources shall be delimited and the ecological sea use red line shall be observed strictly.

\subsubsection{Improve the formation and dynamic adjustment mechanism of sea area use fee}

Obtain current data through investigation, realize the classification and grading of the national seas, improve the formation and dynamic adjustment mechanism of sea area use fee and realize the paid utilization of the sea areas more scientifically and rationally.

\section{References}

1. Chen Mingjian and He Guoxiang 2002 Journal of Oceanography Study on the Index System of Sea Area Classification and Gradation in China Volume 24 Issue 3 PP 18-27

2. Cai Yueyin, Zhao Quanmin and Wang Weiwei 2012 Marine Development and Management Current Situation and Suggestion of Paid Utilization System in China's Sea Area Volume 11 PP 9-13

3. Li Peijin 2006 Liaoning Normal University Theoretical and Empirical Study on Marine Use Evaluation

4. Zhao Jianhua, Zhao Quanmin, Miao Fengmin, et al. Study on Classification Grading Factors and Indexes of Sea Area Use [C]// Papers compilation in 2005 academic annual meeting of Chinese Society of Oceanography, Beijing: Chinese Academic Journal (CD) Electronic Magazine Co., Ltd. PP 428-433

5. Wang $\mathrm{Li}$ and Miao Fengmin 1999 Marine Development and Management The Theoretical Study on the Determination of Paid Utilization Price in Sea Area Volume 16 Issue 1 PP 21-24 
6. Wu You and Cao Keyu 1998 Statistical Study Reflections on Natural Resources and Environmental Accounting Volume 15 Issue 2 PP 59-63

7. Hao Feng 2005 Statistics \& Information Forum International Progress in Capital Stock Accounting and Its Implications for China Volume 20 Issue 5 PP 14-17

8. Zhang Hongliang 2007 Journal of Shanxi University of Finance and Economics Valuation Theory and Method Research of Natural Resource: from the Perspective of a Macro Environmental Accounting Volume 29 Issue 3 PP 15-20

9. Hou Xiyong, Liu Jing, Song Yang and Li Xiaowei 2016 Proceedings of the Chinese Academy of Sciences Ecological Environmental Impacts and Policy Suggestions on the Development and Utilization of China Mainland Coastline Volume 31 Issue 10 PP 1143-1150

10. Hou Xiyong, Hou Wan and Wu Ting 2016 Journal of Geographical Sciences Morphological Changes of
Main Bays along the Coast of China Mainland since the beginning of the 1940s Volume 71 Issue $1 \mathrm{PP}$ 118-129

11. Feng Zhiming, Yang Yanzhao and Chen Yue 2015 Resources Science Research Progress of National Balance Sheet and its Enlightenment to the Compilation of Natural Resources Balance Sheet Issue 9 PP 1685-1691

12. Zhai Weikang, Xu Wenbin, Li Jin, et al. 2012 Marine Development and Management Analysis of Current Situation Characteristics and Existing Problems of Sea Use in China Volume 29 Issue 3 PP 26-30 